\title{
Actualidade do Ciclo de Krebs
}

\section{Introdução}

No dia de 25 de Agosto de 2000 completaram-se cem anos do nascimento de Hans Krebsi, cujo nome está associado ao ciclo de Krebs (do ácido cítrico ou do ácido tricarboxílico), tradicionalmente matéria de estudo na Bioquímica. A sua importância ultrapassa os domínios clássicos da Bioquímica e os mais recentes conhecimentos sobre o ciclo permitem uma abordagem mais interdisciplinar, mais acessível para pessoas vindas de áreas fronteiriças à Bioquímica. Estes desenvolvimentos têm permitido uma melhor compreensão dos mecanismos de algumas enzimas e tornam possiveis novas aplicações em diversos domínios (por exemplo em biotecnologia e em medicina).

\section{Ciclo de Krebs: aspectos históricos}

Durante a segunda década do século XX alguns investigadores detectaram a transferência de átomos de hidrogénio em alguns ácidos orgânicos em suspensões de tecidos animais moídos. Estas experiências foram feitas em condições anaeróbias e usaram como indicador 0 azul de metileno. Com estas experiências foi possivel concluir a existência de desidrogenases naqueles tecidos. Nos anos 30 determinou-se a velocidade de consumo de oxigénio molecular através de medições com manómetros em suspensões de tecidos moídos. Verificou-se a oxidação de alguns ácidos orgânicos a dióxido de carbono e foi mesmo possivel detectar a sequência de oxidação do succinato. Em 1937, Krebs e o seu assistente W. A. Johnson concluiram que existia uma sequência de reacções organizadas de forma cíclica. Esta conclusão foi atingida a partir de trabalhos com suspensões de músculos utilizados pelos pombos durante o voo (tecidos sujeitos a elevado gasto energético, quando em acção). Para tal nem sequer utilizaram a técnica de marcação isotópica que começou a ser experimentada na mesma altura. É este ciclo que hoje é conhecido pelo nome de Krebs [1,2].

\section{Ciclo de Krebs: aspectos metabólicos gerais}

O ciclo de Krebs está presente, com pequenas variantes, tanto nos microrganismos - como por exemplo a Escherichia coli - como em animais superiores - caso do homem. Porém, para ser mais bem compreendido, é preciso mencionar a fonte principal de energia do organismo - a glicose (fig. 1a) - e os seus processos de degradação.

A glicólisei é o processo através do qual a molécula de glicose (fig. la) é degradada numa sequência de dez reacções

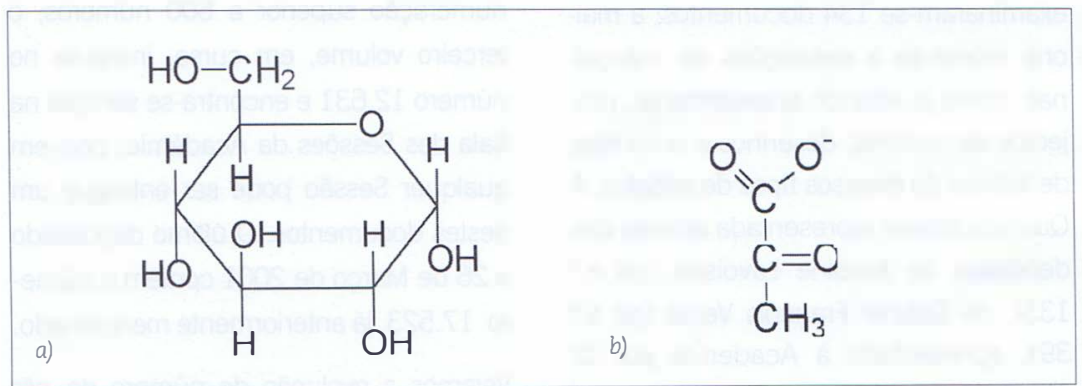

Departamento de Química, Universidade Estadual de Maringá, Av. Colombo 5790, 87020-900 Maringá - PR BR-Brasil

${ }^{1}$ Endereço actual: Coordenadoria de Pós-Graduaçāo, Instituto de Química - UFSCar, C. P. 676, 13565-905 - São Carlos - SP; e-mail: aparecido@dq.ufscar.br

${ }^{2}$ Endereço actual: Coordenadoria de Pós-graduação, Instituto de Quimica - UNICAMP, C.P. 6154, CEP 13083-970 - Campinas - SP; e-mail: RVP: robvalentim@zipmail.com.br e FSY: fseiji@hotmail.com

${ }^{3}$ Endereço permanente: Centro de Quimica Estrutural, Institulo Superier Técnico, 1049-001 Lisboa P-Portugal; e-mail: pca1950@popsrv.ist.utı.pt 
em duas moléculas de piruvato (fig. 1b). Durante este processo muita da energia livre libertada é armazenada sob a forma de ATP (do inglês, Adenosine TriPhosphate)

A glicólise é a via central de degradação da glicose na maioria dos organismos vivos. Existem três vias importantes que podem ser seguidas pelo piruvato (ver fig. 2). Todavia, nem todos os organismos utilizam as três formas.

Numa das vias, como acontece em alguns microrganismos em anaerobiose, o piruvato formado a partir da glicose pela via glicolítica é convertido em etanol e dióxido de carbono, através de um processo chamado fermentação alcoólica (sem a qual não seria possivel a produção do vinho ou da cerveja).

A segunda via possível de consumo do piruvato é a sua redução a lactato. Esse processo ocorre em alguns tecidos ani- mais quando funcionam anaerobiamente, em especial, o músculo esquelético durante um processo envolvendo actividade física intensa. A formação do ácido láctico por acção de bactérias pode originar o leite fermentado (sem esta actividade não seria possivel produzir o iogurte) e, ainda, o chucrute (tão de agrado dos apreciadores da cozinha alemã) obtido pela fermentação do repolho.

Nos organismos aeróbios o piruvato formado a partir da glicólise é oxidado, perde o seu grupo carboxílico, libertado na forma de dióxido de carbono, e forma o grupo acetilo da acetil coenzima A. Esta é a via de degradação do piruvato nas células aeróbias animais e vegetais [3a].

Ao longo da sua vida, os organismos omnivoros consomem uma grande variedade de alimentos complexos, tanto de origem animal, como vegetal. No seu corpo, esses alimentos são transformados em substâncias mais simples, tais como os monossacáridos. Entre os estágios terminais da oxidação dessas substâncias salienta-se um ciclo de reacções enzimaticamente assistidas, onde 0 ácido cítrico ${ }^{\text {iii }}$ (dai o nome alternativo do ciclo de Krebs) é um intermediário importante desse processo. O ciclo, embora seja mencionado na literatura por si só por assim ser mais fácil a sua compreensão, não surge isoladamente no organismo. Está associado a outros processos de uma forma muitas vezes complexa, o que o torna relevante em diversas funções metabólicas. As principais funções às quais o ciclo de Krebs está associado são:

1) Produção da maior parte do dióxido de carbono formado nos tecidos;

2) Fornecimento de grande parte das coenzimas reduzidas que são utilizadas na cadeia respiratória e parti-

figura 2 Vias de degradação do piruvato (adaptado de[3])

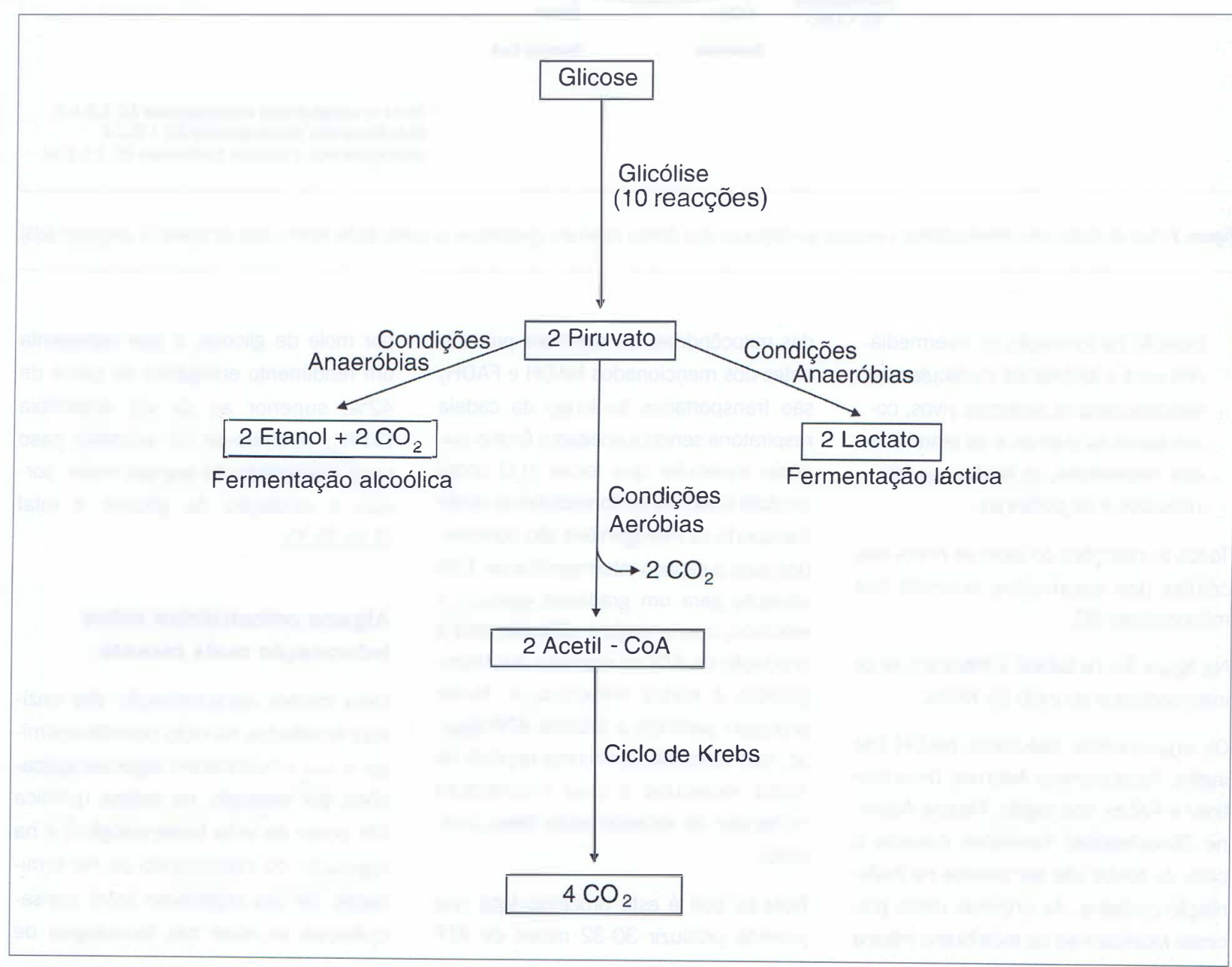




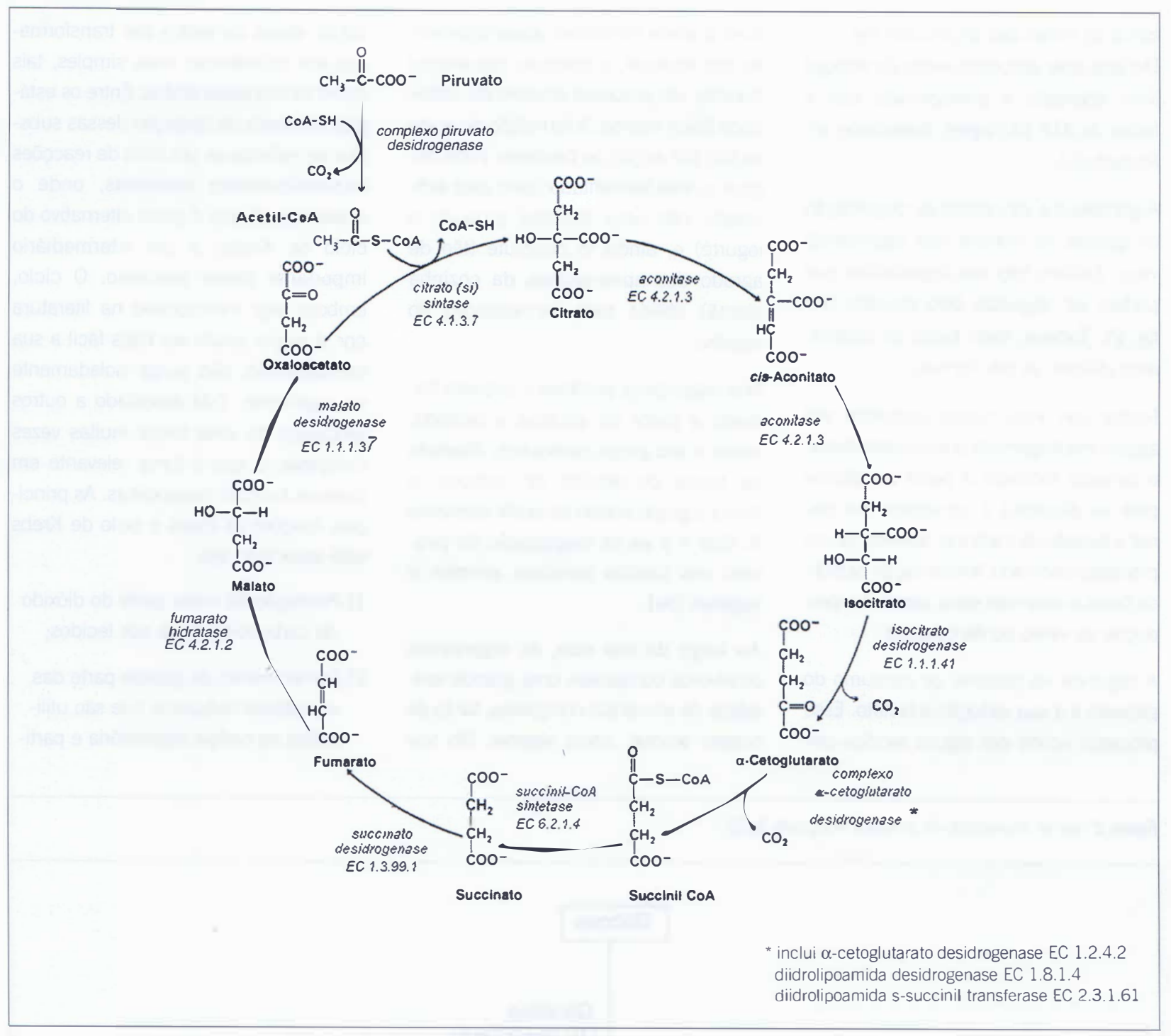

figura 3 Ciclo de Krebs: seus intermediários e enzimas participantes (por clareza de leitura apresentam-se outros dados sobre o ciclo na tabela 1); adaptado de[3].

cipação na formação de intermediários para a sintese de moléculas essenciais para os sistemas vivos, como sejam as purinas e as pirimidinas dos nucleótidos, os lípidos, os aminoácidos e as porfirinas.

Todas as reacções do ciclo de Krebs nas células dos eucariontes ocorrem nas mitocôndrias [4].

$\mathrm{Na}$ figura 3 e na tabela 1 mostram-se os intermediários do ciclo de Krebs.

Os equivalentes redutores $\mathrm{NADH}$ (do inglês, Nicotinamide Adenine Dinucleotide) e $\mathrm{FADH}_{2}$ (do inglês, Flavine Adenine Dinucleotide) formados durante 0 ciclo de Krebs vão ser usados na fosforilação oxidativa. As enzimas deste processo localizam-se na membrana interna das mitocôndrias. Os electrões provenientes dos mencionados $\mathrm{NADH}$ e $\mathrm{FADH}_{2}$ são transportados ao longo da cadeia respiratória sendo o aceitador final o oxigénio molecular que forma $\mathrm{H}_{2} \mathrm{O}$ como produto final. Como consequência deste transporte os hidrogeniões são bombeados para o espaço intermembranar. Esta situação gera um gradiente químico e eléctrico, cuja energia é utilizada para a produção de ATP no regresso dos hidrogeniões à matriz mitocondrial. Neste processo participa a enzima ATP-sintase, que funciona como uma espécie de motor molecular e cuja arquitectura molecular foi recentemente determina$\mathrm{da}[6]$.

Note-se que é este processo total que permite produzir 30-32 moles de ATP por mole de glicose, o que representa um rendimento energético de cerca de $42 \%$, superior ao da via anaeróbia (31\%); obtendo-se no primeiro caso uma quantidade de energia maior porque a oxidação da glicose é total $[2,3 a, 3 b, 5]$.

\section{Alguns comentários sobre informação mais recente}

Uma melhor caracterização das enzimas envolvidas no ciclo permite optimizar a sua actividade em algumas aplicações, por exemplo, na síntese química (do ponto de vista biotecnológico) e na regulação do crescimento ou na eliminação de um organismo (com consequências ao nível das tecnologias de 
produção animal, medicina, etc.). Um melhor conhecimento das funções das enzimas passa pelo entendimento dos mecanismos durante a sua acção e uma das ferramentas importantes é a determinação das suas estruturas. $\mathrm{Na}$ década de 90 do século XX os conhecimentos sobre os centros activos das enzimas aumentaram consideravelmente. Actualmente, já foram determinadas as estruturas de praticamente todas as enzimas participantes no ciclo de Krebs ${ }^{\text {iv }}$ através das técnicas de difracção de raios-X e espectrometria de RMN, técnicas que não estavam acessiveis aos investigadores na primeira metade do século XX. Algumas dessas estruturas contêm os substratos ou os produtos das reacções (outras ainda inibidores) coordenados ao centro activo das enzimas, o que torna, assim, possivel "visualizar" as etapas da catálise. Todavia não se conhece o conjunto completo de tais etapas para o mesmo organismov, embora a generalização dos conhecimentos possa ser feita devido à consistência encontrada entre muitos dados experimentais provenientes de diferentes sistemas vivos.

Adiante apresentar-se-á resumidamente alguns aspectos importantes das enzimas activas no ciclo de Krebs, salientando a lógica da sua escolha para a função que desempenham.

\section{As funções nos iões metálicos no ciclo de Krebs}

Muitas enzimas têm iões metálicos no centro activo, isto é, são metaloenzimas. Nestes casos alguns conhecimentos sobre estes elementos, isto é, das suas propriedades especificas do ponto de vista químico associadas à sua disponibilidade, permitem entender as razões da sua escolha em biologia [7]. Sobre estas características dos elementos metálicos refiram-se, por exemplo, o tipo de complexos que formam, a sua geometria de coordenação e a existência ou não de vários estados de oxidação.

Algumas das enzimas envolvidas no ciclo de Krebs não contêm nenhum metal no seu centro activo (ver tabela 1) embora noutras os iões metálicos tenham um papel determinante. Como exemplo, refira-se o $\mathrm{Mg}^{2+}$, o qual tem uma densidade de carga elevada (consequência do seu pequeno raio iónico $\approx 0,6 \AA$ ) o que lhe permite estabilizar muitas espécies aniónicas também com elevada densidade de carga, como por exemplo os fosfatos[7] (importantes no ciclo de Krebs). Também é atribuído ao $\mathrm{Mg}^{2+}$ o papel de activador ou interruptor de reacções enzimáticas[7]. Estas ca-

tabela 1 Características das reacções e das enzimas participantes no ciclo de Krebs; adaptado de [5]

\section{Reacção}

Tipo de reacção

Condensação

acetil $\mathrm{CoA}+$ oxaloacetato $+\mathrm{H}_{2} \mathrm{O}$

$\rightarrow$ citrato $+\mathrm{CoA}+\mathrm{H}^{+}$

\begin{tabular}{|c|c|c|c|}
\hline citrato $\rightleftarrows$ cis-aconitato $+\mathrm{H}_{2} \mathrm{O}$ & Desidratação & Aconitase & "cluster" Fe-S \\
\hline cis-aconitato $+\mathrm{H}_{2} \mathrm{O} \underset{\gtrless}{ }$ isocitrato & Hidratação & Aconitase & "cluster" Fe-S \\
\hline $\begin{array}{l}\text { Isocitrato }+\mathrm{NAD}^{+} \vec{\gtrless} \alpha \text {-cetoglutarato }+ \\
\mathrm{CO}_{2}+\mathrm{NADH}\end{array}$ & Descarboxilação e oxidação & isocitrato desidrogenase & $\mathrm{M}^{2+}$ \\
\hline $\begin{array}{l}\alpha \text {-cetoglutarato }+\mathrm{NAD}^{+}+\mathrm{CoA} \rightleftarrows \\
\text { succinil-COA }+\mathrm{CO}_{2}+\mathrm{NADH}\end{array}$ & Descarboxilação e oxidação & $\begin{array}{l}\text { Complexo } \alpha \text {-cetoglutarato } \\
\text { desidrogenase }\end{array}$ & * \\
\hline $\begin{array}{l}\text { succinil-CoA }+P I^{\S}+G D P^{\&} \rightleftarrows \text { succinato } \\
+ \text { GTP }^{\&}+\mathrm{Co} A\end{array}$ & Fosforilação & succinil-CoA sintetase & \\
\hline succinato $+F A D \vec{\gtrless}$ fumarato $+F A D H_{2}$ & Oxidação & succinato desidrogenase & $\begin{array}{l}\text { FAD, "cluster" Fe-S } \\
\text { e Fe hémico }\end{array}$ \\
\hline fumarato $+\mathrm{H}_{2} \mathrm{O} \rightleftarrows$ L-malato & Hidrataçāo & fumarato hidratase & \\
\hline $\begin{array}{l}\text { L-malato }+\mathrm{NAD}^{+} \rightleftarrows \text { Oxaloacetato }+ \\
\mathrm{NADH}+\mathrm{H}^{+}\end{array}$ & Oxidação & malato desidrogenase & \\
\hline
\end{tabular}

Cofactor ou grupo prostético

Enzima

citrato (si) sintase 


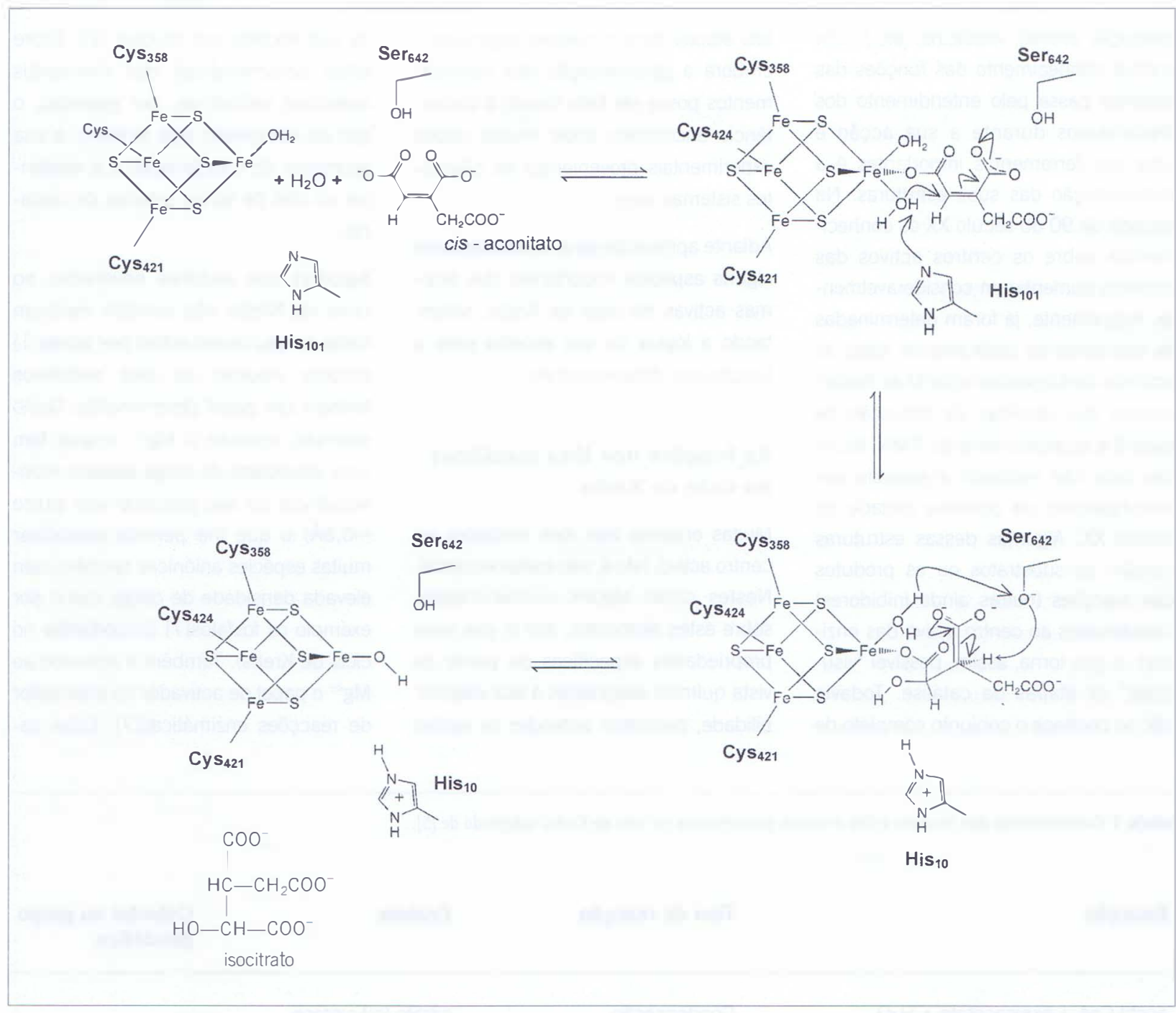

figura 4 Mecanismo simplificado de conversão do cis-aconitato em isocitrato por acção da enzima aconitase (desta só se apresenta o centro activo por questão de simplicidade de representação); adaptado de [14].

racterísticas resultam da formação de complexos com componentes proteicos com constantes de estabilidade baixa ou moderada. Deste facto resulta, por exemplo, para pequenas variações de $\mathrm{pH}$ ou de concentração de outros iões a coordenação (ou descoordenação) do ião $\mathrm{Mg}^{2+}$ à enzima e daí a alteração da sua actividade. No ciclo de Krebs é, por exemplo, reconhecida a importância do ião $\mathrm{Mg}^{2+}$ no complexo a-cetoglutarato desidrogenase[4].

Neste trabalho, a ênfase dada aos metais, resulta da menor divulgação do papel destes no ciclo do ácido cítrico. Não se pretende tratar o assunto duma forma exaustiva, mas apenas referir alguns aspectos estudados mais recentemente. Deve notar-se que a função dos iões metálicos não se restringe apenas a funções estruturais ou catalíticas. Um outro aspecto importante sobre o papel dos iões metálicos relaciona-se com a expressão dos genes associados às enzimas do ciclo de Krebs. Actualmente, têm-se muitas informações sobre o importante papel dos iões dos metais de transição nos processos associados com a biologia molecular. Para mais informações, ver por exemplo [8].

\section{Metaloenzimas no ciclo de Krebs}

O ferro é um dos metais que se sabe com segurança que participa no ciclo de Krebs. Este metal está envolvido em diversos mecanismos biológicos (é o metal de transição mais abundante nos organismos vivos e com funções bem diferenciadas) e, no caso do ciclo de Krebs, é referida a sua acção em quatro sistemas enzimáticos: na aconitase, na citrato sintase, na isocitrato desidrogenase e na succinato desidrogenase [9]. $\mathrm{Na}$ aconitase, o ferro possui características muito especiais, porque está envolvido num "cluster" de ferro-enxofre (é o metal imprescindivel para este tipo de sistemas em biologia, embora possa estar associado com outros metais ${ }^{\mathrm{vi}}$ ); tem uma função que apenas recentemente foi conhecida (em hidroliases), sendo o caso da aconitase o mais bem estudado. Nestas enzimas o ferro está envolvido em reacções de hidratação ou desidratação de substratos e não varia o seu estado de oxidação. Mais conhecidos são os "clusters" de Fe-S que estão 
envolvidos em processos de transferência electrónica, como acontece na enzima do ciclo de Krebs succinato desidrogenase $^{\mathrm{vii}}$.

\section{Aconitase}

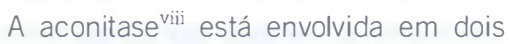
passos do ciclo de Krebs: o primeiro é a conversão do citrato em cis-aconitato e no segundo é a conversão deste em isocitrato (ver fig. 3). Na sua forma inactiva, o "cluster" de ferro-enxofre é um sistema $\mathrm{Fe}_{3} \mathrm{~S}_{4}$, enquanto que, na forma activa, é um sistema $\mathrm{Fe}_{4} \mathrm{~S}_{4}$ (ver fig. 4) ligado covalentemente à proteína por três residuos de cisteína, sendo o quarto átomo de Fe fundamental para o processo catalítico. As reacções envolvendo a eliminação de água para formar uma dupla ligação (como é o caso da formação do cis-aconitato a partir do citrato) são favorecidas pela presença de bons electrófilos, como é o caso dos catiões metálicos 'os quais têm comportamento de ácidos de Lewis). A aconitase na sua forma activa neste sistema comporta-se como ácido de Lewis, análogo à função mais conhecida do Zn em biologia [7].

$\mathrm{Na}$ fig. 4 esquematiza-se apenas um dos passos da aconitase no ciclo de Krebs, na formação do isocitrato a partir do cis-aconitato. Como consequência da coordenação ao ferro, a molécula de água fica activada (o resíduo de histidi- na participa na reacção ácido-base aceitando um hidrogenião) e permite que o grupo resultante efectue um ataque electrófilo a um carbono do substrato também activado pela sua coordenação ao ferro. Durante as várias etapas da reacção, a geometria de coordenação do ferro altera-se. Esta é uma das razões da utilização dos metais de transição em biologia: por terem orbitais "d" disponíveis podem apresentar geometrias variáveis, as quais são úteis em processos catalíticos. Por outro lado, os centros metálicos associam-se favoravelmente a moléculas pequenas $-\mathrm{O}_{2}$, $\mathrm{NO}, \mathrm{CO}, \mathrm{H}_{2} \mathrm{O}$.

\section{Isocitrato desidrogenase}

Uma outra enzima para a qual é atribuído papel fundamental a um ião metálico é a isocitrato desidrogenase que catalisa em duas etapas a descarboxilação oxidativa do isocitrato a $\alpha$-cetoglutarato. Duas enzimas catalisam esta reacção sendo cada uma referida pelo cofactor: uma usa o $\mathrm{NAD}^{+}$(EC 1.1.1.41) $)^{1 \mathrm{x}}$ e a outra o $\mathrm{NADP}^{+}$(do inglês Nicotinamide Adenine Dinucleotide Phosphate) (EC 1.1.1.42). A primeira está normalmente associada com reacções de degradação e a segunda com reacções de biossíntese. Ambas precisam de um ião divalente, normalmente referido como o ião manganês ou ião magnésio $[15,16]$. A primeira participa no ciclo de Krebs, mas ainda não é conhecida a sua estrutura. Da segunda enzima já foram determinadas algumas estruturas, e consultando as apresentadas no endereço electrónico referido na nota $\mathrm{v}$ é possivel encontrar a enzima coordenada ao $\mathrm{Mg}^{2+}$, ao $\mathrm{Ca}^{2+}$, ao $\mathrm{Mn}^{2+}$ sem qualquer ião metálico. $\mathrm{O}$ iāo metálico está coordenado com uma geometria tipo octaédrica ao isocitrato pelos grupos carboxílico e hidróxilo, ver fig. 5 , a duas cadeias laterais de residuos de ácido aspártico que estão no centro activo da enzima, e ainda a duas moléculas de água [17]. 0 ião metálico funcionando como ácido de Lewis permite a activação da molécula do substrato. No mecanismo reaccional dá-se a oxidação do grupo hidróxilo no isocitrato, obtendo-se uma cetona, e depois a descarboxilaçāo (ver fig.5). A formaçāo de um carbaniāo intermediário durante a quebra da ligação $\mathrm{C}-\mathrm{C}$ necessita de uma entidade química estabilizadora (um grupo electrófilo, um ácido de Lewis). 0 $\mathrm{Mn}^{2+}$ tem essas características químicas e quase todas as suas funções metabólicas são intracelulares, embora seja mais lábil do que $0 \mathrm{Mg}^{2+}$ [7] e essa pode ser uma das razões pela qual durante 0 processo de cristalização é mais fácil a apoenzima coordenar-se com o último ião. $\mathrm{O} \mathrm{Ca}^{2+}$, pelas suas dimensões maiores que as dos outros dois, é entre os iões divalentes o que mais dificilmente activaria o substrato. A determinação inequívoca do ião envolvido pode ser

figura 5 Interacção (apresentada numa forma muito simplificada) entre um ião divalente com carateristicas de ácido de Lewis activador e o isocitrato (são omitidas as outras entidades do centro activo da enzima).<smiles></smiles>

isocitrato

$\mathrm{R}-\mathrm{COO}^{-}$

$\mathrm{R}^{\prime}-\mathrm{CH}_{2} \mathrm{COO}^{-}$ 
complexa e eventualmente pode depender das concentrações relativas para cada caso específico.

\section{Algumas particulariedades das metaloenzimas do ciclo de krebs}

Embora se tenha dado ênfase ao papel activador dos iões metálicos como ácidos de Lewis, é bom recordar que cada uma das reacções mencionadas tem especificidade própria (ver tabela 1). Cada enzima está envolvida em reacções com características diferentes. A aconitase está envolvida em reacções de desidratação e hidratação, a isocitrato desidrogenase em reacções de descarboxilação e oxidação e a succinato desidrogenase em reacções de oxidação. Isto significa que a escolha dos iões está também dependente de outras características, tais como: os seus vários estados de oxidação, a estabilidade das entidades nas quais eles participam ao longo do processo catalítico, etc.

\section{Alguns aspectos dos mecanismos de algumas enzimas do ciclo de Krebs}

A relevância do ciclo de Krebs estende-se a diferentes áreas das ciências biológicas. Torna-se agora possivel referir duma forma sumária a importância de algumas das suas reacções, entre outros exemplos, na produção industrial por via biotecnológica de ácido cítrico ou em medicina.

Desde o final do século XIX que 0 ácido cítrico é obtido em larga escala pela fermentação de cana de açúcar ou de melaço por acção do fungo Aspergillus niger. Estas aplicações têm sido estudadas para várias estirpes desta espécie e também de outras espécies do mesmo género, como seja o $A$. wentii. Neste caso foi possivel concluir que a adição de ferro ao meio prejudica a produção do ácido cítrico [18]. No ciclo de Krebs (ver fig.3) a aconitase actua sobre o ácido cítrico. Um teor baixo de ferro faz com que a aconitase fique na sua forma inactiva e por isso não actua sobre o ácido cítrico, isto é, ele não é consumido, causando um aumento na sua concentração em solução. Este exemplo permite entender que um melhor conhecimento das reacções do ciclo de Krebs (o que passa naturalmente pela compreensão dos mecanismos de acção das enzimas) torna possivel, entre outros aspectos, optimizar de um ponto de vista biotecnológico a produção de qualquer outro produto obtido num passo intermediário do ciclo. É portanto fundamental o conhecimento do metabolismo do organismo que se pretende utilizar para escolher as condições de actividade óptimas (podem envolver diversos parâmetros como a concentração, a temperatura, o pH, etc.) para a enzima que participa na reacção de formação do produto pretendido e que em simultâneo seja inibida a actividade da enzima do passo seguinte do ciclo, o que impediria o consumo do produto anteriormente obtido. Cada enzima tem um intervalo dos seus parâmetros de actividade adequado para a sua utilização. Pode acontecer que alguns desses valores sejam comuns aos de outra enzima que recorra ao produto obtido como substrato, o que inevitavelmente fará decrescer a concentração do composto pretendido.
A um outro nível, refere-se a aplicação destes conhecimentos em medicina. $\dot{E}$ sabido que a próstata dos seres humanos e de outros animais acumula e segrega quantidades elevadas de citrato. Concomitantemente a este facto está associado um elevado teor de ião zinco no mesmo órgão. Este em teor elevado inibe a actividade da aconitase mitocondrial, o que impede as reacções posteriores do citrato e provoca o decréscimo de produção de energia celular na forma de ATP. No caso do cancro da próstata o teor do ião zinco diminui e, desta forma, aumenta a actividade das enzimas dos passos seguintes do ciclo de Krebs. Consequentemente aumenta a produção de ATP necessária ao desenvolvimento e propagação das células cancerosas. É compreensivel que um melhor conhecimento das interaç̧ões dos iões dos metais com as enzimas do ciclo de Krebs nos dará informações, que neste caso permitirão novas estratégias na prevenção e no tratamento do cancro da próstata[19].

\section{Comentário final}

No centenário do nascimento de Hans Krebs e mais de sessenta anos após os seus estudos sobre o ciclo, que tem o seu nome, é possivel verificar a importância que o mesmo tem no domínio das ciências biológicas e em campos tecnológicos. Na realidade, o ciclo de Krebs e as suas reacções estão envolvidos numa teia complexa de interacções que se relacionam com muitos tipos de metabolitos, sendo estes conhecimentos importantes para novas aplicações.

\section{Agradecimentos}

J. A. L. da Silva agradece a bolsa da CAPES que lhe tornou possivel exercer o cargo de Professor Visitante na Universidade Estadual de Maringá e que permitiu a elaboração deste trabalho.
Aparecido Junior de Menezes, Robson Valentim Pereira e Fernando Seiji Yonehara agradecem a CAPES que através do Programa Especial de Treinamento PET - DQI/UEM tornou possível a concretização deste artigo.
Os autores agradecem ao Prof. J. J. R. Fraústo da Silva as sugestões dadas que permitiram melhorar este texto; e à Dr. Sónia Cunha a leitura final do texto.

\section{Referências}

[1] J. T. Edsall, Naturc, 366 (1993) 417 